\title{
A Case Report of Delirium and Literature Review of Dementia in COVID-19 Process
}

\author{
COVID-19 Sürecinde Deliryum Olgu Sunumu ve Demansın Literatür Taraması
}

\author{
Meryem Tuba SÖNMEZ \\ (D) 0000-0003-4418-7906 \\ Tülin AKTÜRK \\ (D) 0000-0003-1818-1578 \\ Hikmet SAÇMACI \\ (D) 0000-0003-1480-0562
}

Bozok University Faculty of Medicine Department of Neurology, Yozgat, Turkey

\section{Corresponding Author Sorumlu Yazar \\ Meryem Tuba SÖNMEZ \\ mtubas@gmail.com}

Received / Gelis Tarihi : 19.08 .2020

Accepted / Kabul Tarihi : 11.11.2020

Available Online /

Çevrimiçi Yayın Tarihi : 25.11.2020

\begin{abstract}
Coronavirus directly infects the nervous system and may cause the course of the existing neurological disease to get worse in those with a chronic neurological disease. People with dementia, which is the most common chronic neurological disease over 65 years old, have serious difficulties in terms of follow-up and treatment of their diseases in the social isolation process. However, due to the risk factors caused by coronavirus disease 2019 (COVID-19), it has become easier for them to go into delirium. These risk factors can be listed as social isolation, inactivity, intense stress, as well as direct invasion of the virus to the central nervous system, the effect of inflammatory cytokines, the effect of sedative drugs used and the effect that develops secondary to other accompanying diseases. This paper provides an assessment regarding the problems experienced by dementia patients in the pandemic process, and their solutions, accompanied by a case presentation.

Keywords: COVID-19; dementia; delirium.
\end{abstract}

ÖZ

Koronavirüs doğrudan sinir sistemini enfekte etmesinin yanı sıra kronik nörolojik hastalığı olanlarda mevcut nörolojik hastalığın daha kötü seyretmesine neden olabilmektedir. Altmış beş yaş üstünde en sık görülen kronik nörolojik hastalık olan demans hastaları sosyal izolasyon sürecinde hastalıklarının takip ve tedavisi açısından ciddi zorluklar yaşamaktadır. Bununla birlikte koronavirüs hastalığı 2019 (coronavirus disease 2019, COVID-19)'un sebep olduğu risk faktörleri nedeniyle deliryuma girmeleri de kolaylaşmıştır. Bu risk faktörleri sosyal izolasyon, hareketsizlik, yoğun stresin yanı sıra virüsün merkezi sinir sistemine direk invazyonu, inflamatuar sitokinlerin etkisi, kullanılan sedatif ilaçların etkisi ve eşlik eden hastalıkların ikincil etkileri olarak sıralanabilir. Bu yazı bir olgu sunumu eşliğinde, demans hastalarının pandemi sürecinde yaşadıkları problemler ve çözümleri üzerine bir değerlendirme sunmaktadır. Anahtar kelimeler: COVID-19; demans; deliryum.

\section{INTRODUCTION}

The coronavirus disease 2019 (COVID-19) pandemic overburdens the healthcare systems of the communities around the world, causing serious mortality and morbidity. Accumulated experiences show that the disease is not specific to lung only, and may progress with involvement of many organs and systems. Especially, the symptoms and findings of the central nervous system and the peripheral nervous system show a wide variety (1). Coronavirus directly infects the nervous system and it may cause the course of the existing neurological disease to get worse in those with a chronic neurological disease. Dementia patients are one of the most affected disease groups. It has been reported that the elderly with dementia are the main risk factor for the severity of COVID-19 infection (2). 
The recent papers discussed the possible difficulties to be experienced by dementia patients in the social distancing and home isolation period due to the pandemic (1). Understanding and evaluating difficulties experienced by dementia patients as from early stages cause them to have difficulties in acting and following restrictions as required in the pandemic process, leading to an increased risk of infection transmission. In addition to behavior problems, all patients with a chronic disease are considered to be at increased risk of COVID-19, regardless of age. The immunity system is weakened as the age advances and with the presence of accompanying chronic diseases, contributing to the risk of COVID-19. In the pandemic process, many clinics suspended healthcare services, which led to interruptions in the control and follow-up of dementia patients. Especially, the progression of dementia presentation and the presence of delirium caused serious difficulties for both patient relatives and caregivers.

During the COVID-19 pandemic process, new practices have been implemented, which can be also considered new for many clinics. The technological facilities such as smart phone applications or video conference have been introduced to support patients and their relatives. With the telemedicine method, somatic neurological evaluation is not fully possible, but neuropsychological tests can be applied. It was reported that especially the follow-ups by video conference are at least as effective as clinical followups in evaluating cognitive functions and daily life activities of patients (3).

This paper aimed to review the status of patients with dementia representing a common chronic neurodegenerative disease group in the pandemic process, accompanied by a case presentation.

\section{CASE REPORT}

The following case illustrates the difficulty that may be experienced in treating excessive stress-induced delirium in patients with dementia, especially when stressors continue and the clinical support cannot be reached. It also illustrates the need in such cases for prolonged antipsychotic treatment and the ultimate good prognosis. The authors received informed consent to publish his case. A 86-year-old man with a history of hypertension, atrial fibrillation, and mild Alzheimer dementia was accepted to the neurology outpatient clinic for altered mental status after his family noted a change in the patient's behavior. His wife told that for about 3 months, in the social distancing and home isolation period due to the pandemic, he was deeply worried. For example, as soon as he woke up early in the morning, he was wearing his mask and was sitting with the mask on his face all day, although there was no one else at home but his wife. When he started acting aggressively and his sleep pattern was disrupted at night, they tried to contact their doctor, but failed because the clinic was closed due to the pandemic. However, they did not want to go to another medical center due to the concern that coronavirus could be transmitted. For the past few days, the patient's appetite waned, and he became progressively more lethargic, not eating for over 30 hours. There were no reported changes to the patient's medications which included donezepil, metoprolol, edoxaban, and hydrochlorothiazide. There was no significant history or complaint associated with the infection.
The patient appeared comfortable in bed. He was sleepy, but easily aroused. Initial vital signs were as follows: heart rate, 115 beats/minute; respiratory rate, 12 breaths/minute; blood pressure, $120 / 70 \mathrm{mmHg}$; and oral temperature, $36.3^{\circ} \mathrm{C}$. Oxygen $\left(\mathrm{O}_{2}\right)$ saturation was $97 \%$ in room air.

His systemic examination was normal. He was oriented to person only and responded appropriately to simple questions, intermittently following one-step commands. His orientation to place and time was impaired. He was unable to attend and required redirection throughout the interview (According to his wife, this behavior was different than his baseline). In his somatic neurological examination there were no focal neurological deficits. His reflexes were normal throughout.

His routine blood and urine tests were normal. Although his lungs were clear during his examination, radiological examinations of the lungs performed due to the pandemic were normal. No abnormality detected on computed tomography. Brain magnetic resonance imaging revealed global atrophy and no acute abnormality that could explain the patient's current condition was found.

Assessment of this patient suggested a diagnosis of delirium due to intense anxiety in the background of Alzheimer dementia.

Oral quetiapine $12.5 \mathrm{mg} /$ day was began and it was gradually increased to $37.5 \mathrm{mg} /$ day. Forty eight hours later his orientation and concentration had completely improved. Escitalopram $5 \mathrm{mg}$ /day was began and planned to increase to $10 \mathrm{mg} /$ day after 10 days. Thus, the patient was discharged, but continued to take quetiapine 25 $\mathrm{mg} /$ day in the evenings additionally to escitalopram and donepezil $10 \mathrm{mg} /$ day. Four weeks later upon follow up, he was cheerful and willing to communicate. He was oriented to person, place and time. According to his wife, his behavior was back to his baseline. Mini mental state examination score was $24 / 30$. It was planned to continue taking escitalopram $10 \mathrm{mg} /$ day, donepezil $10 \mathrm{mg} /$ day, and also quetiapine (as it removed night sleep interruptions) $12.5 \mathrm{mg} /$ day in the evenings. Due to the ongoing COVID-19 pandemic and isolation, monthly phone calls and visits and a clinical check-up 6 months later were scheduled.

\section{DISCUSSION}

The symptoms and findings of the central nervous system and the peripheral nervous system caused by COVID-19 show a wide variety. A study from Wuhan, where the virus first emerged and spread, reported that 78 of 214 patients had findings suggesting a neurological system involvement, and the neurological system findings of the patients were divided into 3 groups. Accordingly (4);

- Findings suggesting central nervous system involvement (headache, dizziness, acute stroke, loss of consciousness, ataxia, seizure)

- Findings suggesting peripheral nervous system involvement (loss of taste and smell, blurred vision, neuropathic pain)

- Findings suggesting skeletal muscle involvement were found.

Although some of the pathogenetic studies about the diseases caused by the virus in the nervous system are explained, many studies are ongoing. Detection of the genetic material of the virus in CSF examinations as well 
as of the coronavirus within the neuron in autopsy examinations is remarkable in terms of neurotropism of the disease $(5,6)$.

It was reported that the virus causes the direct involvement of the nervous system as well as serious immune reactions and creates a cytokine storm, leading to organ or system damage (7).

It has been reported that the elderly with dementia are the main risk factor for the severity of COVID-19 infection (2). Considering several papers reporting that the renin angiotensin system adversely affects neurodegenerative processes, it may be suggested that the virus may also contribute to the neurodegenerative process using ACE2 receptors (8). The recent papers mentioned the contributions of the renin-angiotensin system to the neurodegenerative process in diseases with neurodegeneration such as dementia (9). Thus, the relationship between COVID-19 and the renin-angiotensin system is remarkable.

A study from the UK reported that regardless of preexisting dementia, patients with ApoE e4e4 allele are at increased risk of COVID-19 infection (10). This is an important finding since it is known that especially those with the ApoE e4e4 (homozygous) genotype are at significantly increased risk of dementia and delirium (11). However, further studies are needed to understand the relationship between the severity of COVID-19 disease and ApoE genotypes.

Dementia often accompanies patients with delirium. However, in patients with COVID-19, the risk of delirium was found to be high due to direct invasion of central nervous system, induction of inflammatory cytokines, the effect of sedative drugs, prolonged mechanical ventilation duration, sedentary life, social isolation and the secondary effects of other accompanying organ failure (12).

In our case report, it is described that a patient diagnosed with Alzheimer's dementia, who was not infected with coronavirus infection, had delirium due to social isolation and intense stress during the pandemic process. Through this case report, we find it useful to review the literature on the problems and solutions experienced by dementia patients during the pandemic process.

Dementia patients have limited access to right sources about the COVID-19 pandemic. They may have difficulties in understanding and implementing the public health measures such as wearing a mask and maintaining the social distance. Ignoring the warnings and failing to comply with quarantine measures may put them at higher risk of infection (1). In many countries, old people tend to live at their homes or residential homes alone or with their partners. Increased social distancing prevents further spread of COVID-19; however, it puts further restrictions on individuals with limited knowledge about telecommunication and those in need of personal assistance. Reduced visits by family members, restriction of social activity programs or group activities as per the health policies to decrease the risk of infection may cause them to feel themselves lonely and abandoned (1).

The individuals with dementia are likely to have accompanying diseases, such as cardiovascular disease, diabetes and pneumonia, which would affect the progress and management of dementia (13). It was reported that pneumonia-related deaths were twice more in individuals with dementia in the non-pandemic period (14). Consequently, individuals with dementia are at increased risk of COVID-19 infection (15). The reported comorbid conditions were associated with bad outcomes, including death, in dementia patients with COVID-19 (16).

The need of follow-up of patients in wards or intensive care units due to COVID-19 may cause stress or behavioral problems in them. Hypoxia, as the typical clinical characteristic of COVID-19, may trigger delirium. All of these may increase the need for support of patients with dementia as well as their care costs (1).

Patients with mild cognitive impairment and mild dementia may fail to comply with the recommendations given by public health officials to prevent infection, such as paying attention to hand hygiene, closing mouth and nose while coughing, keeping social distancing with others or isolation $(15,17)$. Those with more severe dementia will not understand most of these recommendations or not remember things to do when appropriate, due to general cognitive impairment. Behavioral and psychological symptoms of dementia such as motor agitation or wandering may weaken isolation and protection efforts. With rapid increase in the number of COVID-19 cases, the healthcare systems around the world have been negatively affected with interruptions in the healthcare services. Elective and non-emergency care services have been suspended in many affected areas. Due to the social isolation, individuals with dementia, who rely on their families or healthcare providers to remember to take their medications or to get support, are at risk of abrupt discontinuation of their medications.

The COVID-19 outbreak disrupts the active care of individuals with dementia as well as their basic routines supporting their mental health. Social outcomes of the pandemic may cause fear, anxiety and anger. They will disrupt any social interactions after some time. The lack of physical intimacy may cause an increase in loneliness and sadness. Exercise is recommended for individuals with dementia, and confinement restricts access to exercise. Sleep disorders are common in those with dementia, which may get worse due to anxiety and loss of social zeitgebers. On the other hand, the lack of physical activity and sleep disorders may cause delirium, increasing morbidity and mortality (18).

The use of cholinesterase inhibitors and memantine is common in the treatment of individuals with Alzheimer and a related disease. The commonly used medications in the treatment of psychiatric symptoms associated with dementia include antipsychotic, antidepressant, antiepileptic and other psychotropic medications (19). Haloperidol, risperidone, olanzapine, quetiapine and ziprasidone are the antipsychotic agents used in the treatment of agitated delirium. In addition, it has been reported that the use of melatonin is beneficial in preventing delirium development and in sleep disorder during the COVID-19 process (20).

Starting a new medication during the pandemic may not be suitable due to insufficient clinical evaluations, blood tests or electrocardiographs. Also, an abrupt discontinuation of the medication or a lack of doctor's visits may play a negative role in the clinical course of such patients (17). Therefore, it will be essential not to interrupt and change the medical treatment of patients. 
The treatment of dementia and related psychiatric symptoms generally involves social and physical interaction such as non-pharmacological interventions, involvement in social groups or exercise groups, and pet therapy. However, reduced social participation due to physical distancing, and patients' inability to use electronic tools and software may prevent these therapies. Therefore, it will be inevitable to encounter with individuals and their relatives with increased medical treatment at the end of the pandemic process (17). The infection symptoms, such as fever, cough, diarrhea, etc. in patients with dementia confirmed the expected worsening of neuropsychiatric symptoms during the COVID-19 outbreak. However, considering such causes and the complex nature of the interaction between COVID-19 and dementia, as per the international recommendations, the supportive care-based approach is recommended for dementia patients all around the world. In particular, the international guidelines include "telemedicine approaches", namely digital revolution recommendations based on multidisciplinary-approach (21).

As recommended by the International Alzheimer's Disease specialists, support is needed for dementia patients and their care givers all around the world. In addition to physical protection from virus infection, mental health and psychosocial support should be provided. For example, mental health care should be provided for psychiatristpsychologists, social care specialists, residential home managers and volunteers, and people living with dementia. Some stress-relief activities such as relaxing or meditation exercises may be provided electronically (1). Dementia support teams may support behavior management via hot lines. Psychological counselors may provide online counseling to care givers at homes and nursing homes (22). Furthermore, patients with dementia should be encouraged to be in more frequent contact with their first-degree relatives or to spend more time with them and to take care of them (1). Especially, video conferences and video playing programs have been shown to be as effective as face-to-face visits in evaluating daily life activities and cognition (23). They are also guiding for the necessity of cerebrospinal fluid evaluation or PET scanning (24). Mobile dementia patients should be encouraged to walk at appropriate spaces such as corridors, while severe dementia patients should be encouraged to do passive exercise movements at their beds to prevent the formation of contracture or bedsores. With the support of their relatives, patients should continue exercises such as remembering loved ones, place-time-person orientation as well as bearing in mind (25). In this regard, patients are recommended to spend more time and share more things with their relatives (26). After the onset of the outbreak in France, a part of hospitalization units was dedicated to COVID-19 positive patients, as acute Alzheimer unit and behavior unit. The staff was provided training on safe management of such patients. They were informed about the fact that the patients may have specific behavior disorders due to quarantine, depending on cognitive impairment. It was planned to support caregivers who cannot visit their loved ones (27). The number of active working staff was reduced for the safety of patients. Thus, it was envisaged to support patients and their families against global disasters with fluent cooperation between risk reduction strategies and Alzheimer research institution -participants, caregivers, research personnel, regulatory agencies, sponsors and funders (28).

For hospitalized and treated dementia patients, one of the important points that should be considered by physicians is the probability of drug interaction. Since antivirals and quinine and azithromycin (less frequently) are metabolized in liver via cytochrome p-450 enzyme system, cholinesterase inhibitors may cause side effects on many systems, especially cardiac side effects, in patients receiving rivastigmine, donepezil and galantamine treatment. Memantine undergoes partial hepatic metabolism and has a low risk for pharmacokinetic/pharmacodynamic drug interaction, which is a more reliable alternative treatment for COVID-19 patients with dementia (29). Non-family personnel should completely use a mask and protective equipment when dealing with hospitalized dementia patients, regardless of their stages, and transfer them to intensive care unit rapidly. It should be also noted that agitation may develop in such patients, which may require sedation. It should be noted that the risk of mortality as well as the likelihood of stress disorders will increase in the patients after anesthesia. Since the number of patients who can understand the interventions is limited (except for mild cognitive impairment), time should not be wasted by serious discussions to obtain consent in order to protect the patient from being in hypoxic and stressful condition (30).

\section{CONCLUSION}

Dementia is the most common neurodegenerative disease in elder population. Increased inflammatory process and cytokine storm due to COVID-19 may adversely affect the course of the disease. Delirium can easily develop in patients with dementia with the addition of secondary diseases or the sociopsychological disadvantages of the pandemic. During the outbreak, the clinical follow-ups should be made via teleconferencing with such patients and their caregivers, and in-house nurse-assisted controls should be performed to continue the existing treatment of patients. It would also be appropriate to provide psychological counseling service to patients and their relatives.

Informed Consent: Written informed consent was obtained from the patient for publication.

Conflict of Interest: None declared by the authors.

Financial Disclosure: None declared by the authors.

Acknowledgements: None declared by the authors.

\section{REFERENCES}

1. Wang H, Li T, Barbarino P, Gauthier S, Brodaty H, Molinuevo JL, et al. Dementia care during COVID-19. Lancet. 2020;395(10231):1190-1.

2. Atkins JL, Masoli JAH, Delgado J, Pilling LC, Kuo CL, Kuchel GA, et al. Preexisting comorbidities predicting COVID-19 and mortality in the UK biobank community cohort. J Gerontol A Biol Sci Med Sci. 2020;75(11):2224-30.

3. Kim H, Jhoo JH, Jang JW. The effect of telemedicine on cognitive decline in patients with dementia. J Telemed Telecare. 2017;23(1):149-54. 
4. Mao L, Jin H, Wang M, Hu Y, Chen S, He Q, et al. Neurologic manifestations of hospitalized patients with coronavirus disease 2019 in Wuhan, China. JAMA Neurol. 2020;77(6):683-90.

5. Moriguchi T, Harii N, Goto J, Harada D, Sugawara H, Takamino J, et al. A first case of meningitis/encephalitis associated with SARSCoronavirus-2. Int J Infect Dis. 2020;94:55-8.

6. Aghagoli G, Gallo Marin B, Katchur NJ, Chaves-Sell F, Asaad WF, Murphy SA, et al. Neurological involvement in COVID-19 and potential mechanisms: A review. Neurocrit Care. 2020; [Epub ahead of print]. doi: 10.1007/s12028-020-01049-4.

7. Nath A. Neurologic complications of coronavirus infections. Neurology. 2020;94(19):809-10.

8. Abiodun OA, Ola MS. Role of brain renin angiotensin system in neurodegeneration: An update. Saudi J Biol Sci. 2020;27(3):905-12.

9. Almeida-Santos AF, Kangussu LM, CampagnoleSantos MJ. The renin-angiotensin system and the neurodegenerative diseases: a brief review. Protein Pept Lett. 2017;24(9):841-53.

10. Kuo C-L, Pilling LC, Atkins JL, Masoli JAH, Delgado J, Kuchel GA, et al. APOE e4 genotype predicts severe COVID-19 in the UK Biobank community cohort. J Gerontol A Biol Sci Med Sci. 2020;75(11):2231-2.

11. Farrer LA, Cupples LA, Haines JL, Hyman B, Kukull WA, Mayeux R, et al. Effects of age, sex, and ethnicity on the association between apolipoprotein E genotype and Alzheimer disease. A meta-analysis. APOE and Alzheimer Disease Meta Analysis Consortium. JAMA. 1997;278(16):1349-56.

12. Kotfis K, Williams Roberson S, Wilson JE, Dabrowski W, Pun BT, Ely EW. COVID-19: ICU delirium management during SARS-CoV-2 pandemic. Crit Care. 2020;24(1):176.

13. Browne J, Edwards DA, Rhodes KM, Brimicombe DJ, Payne RA. Association of comorbidity and health service usage among patients with dementia in the UK: a population-based study. BMJ Open. 2017;7(3):e012546.

14. Foley NC, Affoo RH, Martin RE. A systematic review and meta-analysis examining pneumonia-associated mortality in dementia. Dement Geriatr Cogn Disord. 2015;39(1-2):52-67.

15. Fotuhi M, Mian A, Meysami S, Raji CA. Neurobiology of COVID-19. J Alzheimers Dis. 2020;76(1):3-19.

16. Zhou F, Yu T, Du R, Fan G, Liu Y, Liu Z, et al. Clinical course and risk factors for mortality of adult inpatients with COVID-19 in Wuhan, China: a retrospective cohort study. Lancet. 2020;395(10229):1054-62.

17. Brown EE, Kumar S, Rajji TK, Pollock BG, Mulsant $\mathrm{BH}$. Anticipating and mitigating the impact of COVID-
19 pandemic on Alzheimer's disease and related dementias. Am J Geriatr Psychiatry. 2020;28(7):71221.

18. Ford AH. Preventing delirium in dementia: Managing risk factors. Maturitas. 2016;92:35-40.

19. Davies SJ, Burhan AM, Kim D, Gerretsen P, GraffGuerrero A, Woo VL, et al. Sequential drug treatment algorithm for agitation and aggression in Alzheimer's and mixed dementia. J Psychopharmacol. 2018;32(5):509-23.

20. Zambrelli E, Canevini M, Gambini O, D'Agostino A. Delirium and sleep disturbances in COVID-19: a possible role for melatonin in hospitalized patients? Sleep Med. 2020;70:111.

21. Ferini-Strambi L, Salsone M. COVID-19 and neurological disorders: are neurodegenerative or neuroimmunological diseases more vulnerable? J Neurol. 2020; [Epub ahead of print]. doi: 10.1007/s00415-020-10070-8.

22. Boots L, de Vugt ME, Van Knippenberg R, Kempen GI, Verhey FR. A systematic review of Internet-based supportive interventions for caregivers of patients with dementia. Int J Geriatr Psychiatry. 2014;29(4):331-44.

23. Moo LR, Gately ME, Jafri Z, Shirk SD. Home-based video telemedicine for dementia management. Clin Gerontol. 2020;43(2):193-203.

24. Cuffaro L, Di Lorenzo F, Bonavita S, Tedeschi G, Leocani L, Lavorgna L. Dementia care and COVID-19 pandemic: a necessary digital revolution. Neurol Sci. 2020;41(8):1977-9.

25. Hsu TJ, Tsai HT, Hwang AC, Chen LY, Chen LK. Predictors of non-pharmacological intervention effect on cognitive function and behavioral and psychological symptoms of older people with dementia. Geriatr Gerontol Int. 2017;17(Suppl 1):2835.

26. Acar T, Acıman Demirel E, Afşar N, Akçalı A, Akman Demir G, Alagöz AN, et al. The COVID-19 from neurological overview. Turk J Neurol. 2020;26(2):58108.

27. Ousset PJ, Vellas B. Viewpoint: Impact of the COVID19 outbreak on the clinical and research activities of memory clinics: An Alzheimer's disease center facing the COVID-19 crisis. J Prev Alz Dis. 2020;3(7):197-8.

28. Alzheimer's Disease Research Enterprise in the Era of COVID-19/SARS-CoV-2. Alzheimers Dement. 2020;16(4):587-8.

29. Balli N, Kara E, Demirkan K. The another side of COVID-19 in Alzheimer's disease patients: drug-drug interactions. Int J Clin Pract. 2020;74(10):e13596.

30. Korczyn AD. Dementia in the COVID-19 period. J Alzheimers Dis. 2020;75(4):1071-2. 